\title{
Itinerarios corporales masculinos en Instagram: Análisis de nuevas formas identitarias masculinas en la sociedad de consumo'.
}

\section{The masculine corporal itineraries in Instagram: Analysis of the new masculine identity forms in the consumer society.}

Ismael Ocampo Bernasconi *

\section{Resumen}

El presente trabajo analiza la relación existente entre la identidad masculina y el cuidado estético del cuerpo en un grupo de publicaciones de usuarios de Instagram. Para ello, se trabaja con 141 fotos pertenecientes a diferentes usuarios varones de la red. Partiendo de un eje teórico que une conceptos de los estudios de las masculinidades, de la sociología del cuerpo y de algunas de las teorías de la posmodernidad, se lleva a cabo un análisis cualitativo, tanto de las fotos como de los textos que las acompañan. El análisis muestra que los usuarios persiguen un fin motivacional y relacional con las publicaciones. Así también, se observan formas masculinas hibridas, donde los sujetos analizados convierten en objeto de deseo y de sacrilegio al cuerpo masculino normativo, estigmatizando así su propio yo en la medida en que no se posee plena y permanentemente ese cuerpo idealizado.

Palabras clave: Culto al cuerpo, Instagram, Masculinidades, Posmodernidad, Antropología del cuerpo

\begin{abstract}
This paper analyzes the relationship between male identity and the aesthetic care of the body in a group of Instagram user publications. To do this, we work with 141 photos belonging to different male users of the network. Part of a theoretical axis that unites

${ }^{1}$ Artículo que surge como parte del trabajo de fin de master del autor. Se agradecen los aportes para el presente artículo de Edurne Jabat y Joseán Larrión

* Graduado en Sociología por la Universidad de Alicante y Máster en Dinámicas de cambio en sociedades modernas avanzadas por la Universidad Pública de Navarra. Contacto: mailto:leamsiuy@gmail.com
\end{abstract}


concepts of the studies of masculinities, the sociology of the body and some of the theories of postmodernity, a qualitative analysis is carried out, both of the photos and the texts that accompany them. The analysis shows that the users pursue a motivational and relational purpose with the publications. Also, masculine forms are observed, where the analyzed subjects become an object of sacrilege in the normative masculine body, thus stigmatizing their own self insofar as that idealized body does not fully and permanently repose.

Key words: Cult of body, Instagram, Masculinities, Postmodernity, Anthropology of the body.

Fecha de recepción: Marzo 2019

Fecha de aprobación: Diciembre 2019

\section{Introducción}

El auge de las redes sociales [RRSS] en Internet ha cambiado muchas de las formas de interacción en las sociedades donde se han popularizado. Estos cambios relacionales se dan tanto en la forma en que las personas interactúan entre ellas, como con su entorno y al mismo tiempo, con ellos mismos. Así, el perfil personal en una red social se ha transformado en algo así como un espejo posmoderno, en el cual las personas se observan para reconocerse a sí mismas. Este auto reconocimiento se enmarca en un contexto social caracterizado por el individualismo y el consumo (Lipovetsky, 1991), donde los proyectos de vida han dejado de ser colectivos, para pasar a ser personales (Maffesoli, 2002), guiados por las lógicas mercantiles del capitalismo neoliberal (Bauman, 2003), promoviendo formas identitarias múltiples y diversas, normativizando conductas y estéticas corporales. En este último sentido, el cuerpo de las personas aparece como un espacio en donde éstas identifican su identidad, la cual está influenciada y guiada por el discurso del consumo. Éste es promovido desde los medios de comunicación, fomentándose arquetipos y referentes ácorporales enmarcados en el cuidado del cuerpo y la búsqueda de la juventud eterna (Maffesoli, 2002), generando la reedición contemporánea del culto al cuerpo.

Se puede apreciar dicho fenómeno, en RRSS en Internet tales como: Facebook, YouTube o Instagram. En ellas las personas publican fotos y videos de su día a día, sus actividades, viajes, encuentros y todo lo que se les pueda ocurrir. Así también, en las RRSS muchas personas publican sus transformaciones corporales, dando a conocer al resto de usuarios, nuevos cambios en el corte de pelo así como también, cambios en cuanto al propio cuerpo, como puede ser la pérdida de peso o el aumento de la masa muscular. En esto último, se ha identificado una tendencia en las RRSS, de mostrar en una misma foto el proceso de cambio corporal, conocidas como fotos de before and after (antes y después).

El presente trabajo se plantea identificar cómo dicho suceso se vive en un grupo de hombres en la RRSS Instagram. Los hombres, desde el advenimiento de la modernidad 
en Europa, han desestimado el cuidado de la estética corporal, entendiendo que dicha práctica es propia de las mujeres, por lo que ellas han tenido una mayor presión sociocultural por su apariencia física que los hombres ${ }^{2}$ (Baudrillard, 2009; Velasco Molpaceres, 2019). Para éstos ha existido cierta disociación con sus propios cuerpos, el cual es percibido como una máquina externa que no requiere de cuidado, y por el contrario, carece de control por el propio hombre (De Keijzer, 2016). Pero en las últimas décadas, el hombre ha recuperado su carácter de sujeto erótico (Enguix, 2012), volviéndose el cuidado de la estética corporal masculina una parte importante de la mercadotecnia de consumo (Ferreiro Habra, 2018). Observar las motivaciones existentes en éstos permitirá ver cómo construyen masculinidades a través de la auto-producción y consumo de sus propios cuerpos y así identificar posibles transformaciones en los referentes hegemónicos del ser hombre. El trabajo se plantea el objetivo de: identificar las maneras en que se representan los valores del culto al cuerpo de las sociedades posmodernas de consumo en las identidades masculinas de algunos usuarios de Instagram.

\section{Ejes teóricos}

\section{Consumo, identidad y cuerpo}

Los cambios producidos en el sistema económico-productivo en las últimas décadas han llevado a la transformación de un modelo de base productiva a un sistema de base financiera, con una producción diferenciada y heterogénea y con un carácter espacial global-planetario (Alonso, 2007). Este nuevo modelo productivo requiere cambios en los individuos, en cuanto se espera que éstos estén más predispuestos al consumo, el cual a su vez es diferenciado como su producción, por lo que los consumidores también deben de diferenciarse (Alonso, 2007). Estos cambios están intrínsecamente vinculados a modificaciones producidas en ciertos valores de la modernidad donde, por ejemplo, se suscita la pérdida de sus referentes ideológicos tradicionales, pasando a una búsqueda de estilos de vida, que no simplemente están dirigidos a satisfacer necesidades, sino que buscan generar una identidad del yo (Giddens, 1995). En este sentido, Lash (1997) explica que hay una pérdida de lo fijo en cuanto a los referentes identitarios, los cuales son suplantados por categorías, y las personas se mueven de una en una produciéndose una confusión entre diferencia y distinción.

Estos cambios generan lo que Lipovetsky (1991) denomina proceso de individualización de las personas, en donde se priorizan los objetivos personales por sobre los colectivos. En esta misma corriente, Marc Augé (1994) agrega que en las sociedades actuales, existe una pérdida de referencias tiempo-espaciales que fomenta una ausencia

\footnotetext{
${ }^{2}$ Sobre las presiones socioculturales para tener un cuerpo normativo en las mujeres existe una amplia bibliografía desde los estudios de género y el feminismo. Éstos principalmente se han vinculado al análisis de las representaciones estereotipadas en los medios de comunicación y a los problemas de desorden alimenticio en las mujeres que la consecución de dichos estereotipos contrae en muchas mujeres. Se recomienda de la bibliografía utilizada en este artículo, la revisión en Velasco Molpaceres (2019) para un mayor conocimiento del tema.
} 
de perspectivas futuras e históricas, llevando a que los individuos vivan en un constante presentismo. Sumado a una sobrecarga de información, imágenes y acontecimientos, fomenta que los referentes culturales sean inestables y en los cuales los individuos no puedan sostenerse, lo que conlleva que al individuo no le quede nada más que el propio individuo como referente a seguir.

Por otra parte, y aportando otro enfoque de la individualidad, Rifkin (2010), comenta que, en un mundo tan conectado e interactivo, la exclusividad ha dejado de ser lo importante, dándose paso a que los sujetos sientan la necesidad de ser parte de algo, por lo que la característica principal sería la inclusividad. Siguiendo con este planteamiento, dicha característica fomenta que las personas estén buscando un constante reconocimiento para sentirse integrados a algún colectivo social, por lo que se producen actitudes dirigidas a intentar llamar la atención de los otros, generando nuevas formas de relacionamiento entre las personas (Lasén, 2012). En esta línea, Beck (1998) conecta este proceso con su teoría de la sociedad del riesgo, en la cual existe la paradoja que en una cultura que promueve la individualización, los individuos son más incapaces de subsistir sin en el apoyo de los demás, siendo una sociedad cada vez más interdependiente, generando que los sujetos sientan gran incertidumbre ante dicha dualidad. Para Callejo (2005), la incertidumbre se suple mediante el consumo, el cual termina siendo el factor que otorga seguridad en los individuos, al mismo tiempo que termina siendo un productor de identidades.

Dentro de los distintos tipos de consumo existentes que intervienen en la producción de las identidades, varios autores mencionan la estética corporal como una de las más importantes. Ésta se adquiere por medio del consumo y está regida por las normas del mismo, promovidas desde los medios de comunicación y la publicidad, fomentando que la identidad del yo se logre consumiendo (Bauman, 2003).

Esteban (2004) afirma que el cuerpo posee un carácter contextual, siendo un elemento relacional que se encuentra en permanente construcción, de ahí que introduce el concepto de itinerarios corporales, en cuanto el cuerpo es lugar de vivencia donde se construye constantemente la identidad de los sujetos. Para la autora, las prácticas de género son siempre reflexivo-corporales que surgen siempre de la interacción. Estas prácticas corporales, se viven en un contexto determinado, que impone ciertas normas corporales, que se reproducen mediante la repetición de la práctica socializada, produciendo que las personas terminan asimilando y entendiéndolas como algo natural (Butler, 2002). Al respecto, Preciado (2002) afirma que "las posiciones de género que creemos naturales (masculinas o femeninas) son el resultado de imitaciones sometidas a regulaciones, repeticiones y sanciones constantes" (p.73). Foucault (1998) por su parte, entiende que el poder es un ejercicio corpóreo, que se imprime en las formas y maneras en que nos relacionamos con nuestro cuerpo y con el de los demás, debido a que el poder se encuentra intrínseco en la forma en que conocemos la realidad y en cómo a partir de ésta actuamos y sentimos.

Los medios de comunicación son quienes principalmente promueven arquetipos y referentes corporales enmarcados en el cuidado del cuerpo y la búsqueda de la juventud eterna (Maffesoli, 2002), generando el surgimiento de una reedición contemporánea del 
culto al cuerpo. Baudrillard (2009) explica que "el cuerpo hoy ha llegado a ser objeto de salvación. Ha sustituido literalmente al alma en su función moral e ideológica" (p.155), debido a que ya no es dios quien castiga al individuo si éste no actúa siguiendo su dogma, sino que es el cuerpo, como forma de estatus social, quien castiga al individuo si este no cuida de él. El cuidado del cuerpo propio se ha vuelto un aspecto de vital importancia para muchas personas en los países occidentalizados.

De esta manera, el cuerpo se vuelve un factor disciplinador en las sociedades, debido que las personas deben procurar alcanzar un determinado tipo de cuerpo normativo, que demuestre su eficacia social. Por lo que muchas personas se auto-controlan y autoreprimen con el fin de alcanzar dicho cuerpo, tal como sucede, por ejemplo, en el caso de las dietas (Turner, 1989). El cuerpo se vuelve el único sustento identitario ante un mundo tan inmenso, dinámico y contradictorio (Barreto, 2011), siendo el nuevo destino de las sociedades posmodernas (Salcido, 2010). Éste se encuentra determinado por modelos de vida ligados al consumo y a cánones de belleza (Entwistle, 2002), que normalmente persiguen estructuras dicotómicas de belleza de tipo lindo(a)/feo(a), flaco(a)/gordo(a), fuerte/débil (Finol y Finol, 2008).

\section{Masculinidades y los nuevos cuerpos}

Históricamente ha existido una mayor presión estética corporal hacia las mujeres, mientras que los hombres han relacionado su cuerpo a fines utilitaristas vinculados a la capacidad laboral (Mira, 2015). El cuerpo masculino ha sido auto-percibido como una máquina que no puede ser controlada por el propio hombre, y que solamente podrá ser detenida cuando ésta ya no pueda seguir más. Así, los hombres son socializados a estar disociados de su propio cuerpo, careciendo de capacidades de autocuidado del mismo, siendo esto visto como algo de índole femenino (De Keijzer, 2016). Dicha feminización de la estética y el cuidado corporal proviene desde el siglo XVII en Europa central (Velasco Molpaceres, 2019), generando que duramente mucho tiempo se estigmatizara a todo hombre que cuidase de su cuerpo, feminizándolo (Aguiar de Souza, 1998).

En las últimas décadas se han producido variaciones en los referentes culturales de la masculinidad, donde el cuerpo masculino ha recuperado paulatinamente el carácter de objeto erótico que pudo tener en algún momento de la antigüedad (Aguiar de Souza, 1998). Por lo que en ciertos contextos, el cuerpo masculino ha sido cosificado, normativizado y estigmatizado de manera similar a los cuerpos femeninos (Enguix, 2012). Los nuevos referentes promueven determinados cuerpos masculinos estilizados y atléticos. Mark Simpson (2018), quien en la década de los noventa había introducido el concepto de metrosexual, incorpora ahora el término spornosexual, para hablar de la importancia que tiene el deporte y el mundo del porno en la construcción idearía del cuerpo masculino, en el cual el cuerpo masculino se convierte en un espectáculo en sí mismo.

Este proceso corporal e identitario masculino podría llegar a ser entendido como una feminización del arquetipo masculino (por lo menos en sus formas estéticas) que se produce desde el cine y el ámbito publicitario principalmente, en el cual el cuerpo masculino se vuelve un elemento de consumo al igual que el de las mujeres (Rey Sevilla, 1999). 
Asimismo, estas nuevas exigencias vinculadas a los cánones de belleza para los hombres, han llevado a que algunos hombres comiencen a sentir inseguridades y complejos respecto a su cuerpo (Bordo, 2001). Al respecto, Ferreiro Habra (2018), al analizar los anuncios publicitarios de productos de cuidado estético corporal masculino, encuentra que éstos continúan remarcando los valores tradicionales de la masculinidad, marcando siempre el límite no traspasable del cuidado corporal con el ejercicio de la homosexualidad.

Estas nuevas exigencias estarían produciendo cambios en la forma en que se construye la masculinidad. Connel (1995), desde su ya clásica teoría de la masculinidad hegemónica, explica que la masculinidad funciona mediante la presencia de un referente cultural contextual para los hombres, con el cual los varones, de seguirlo, podrán acceder a los dividendos patriarcales que el sistema de género otorga a la masculinidad en oposición a la femineidad. De esta manera, la masculinidad funciona jerárquicamente a través de un referente cultural masculino, que tiene como punto central su oposición a todo lo femenino (Bourdieu, 2000).

Tradicionalmente, el modelo de masculinidad hegemónica se rige por una serie de mandatos de masculinidad, que delimitan qué es ser un hombre en un contexto determinado. En términos generales, estos mandatos se definen por el hecho de que un hombre debe ser importante para ser considerado como tal (Marqués \& Osborne, 1991), por la negación de todo lo femenino y la heterosexualidad obligatoria del varón (Bourdieu, 2000). A su vez, también se destacan otras características del modelo tradicional hegemónico como: la fuerza física, la neutralidad emocional, la seguridad, el control, la competitividad, la instrumentalidad, la objetividad, la racionalidad, el ser activo, jefe de hogar, proveedor, responsable, autónomo, no rebajarse ante nada ni ante nadie; ser fuerte, no tener miedo (Rodríguez Menéndez, 2007; Boscan, 2008). Segato (2013) explica que la masculinidad es corporativa debido a que no permite a los hombres el cuestionamiento de los mandatos de masculinidad, ni el buscar alternativas a éstos, debido a que siempre se corre el riesgo de ser expulsado de la corporación masculina y ser degradado a la figura del no-hombre, o sea, algo feminizado.

En la actualidad, y en el marco de las sociedades posmodernas, el modelo hegemónico ya no existiría de forma pura, sino que estaría en una constante hibridez (Demetriou, 2001) de referentes culturales múltiples, dinámicos y contradictorios (Hatty, 2000), en donde se produce un desencuentro entre las prácticas y los significados, volviendo menos claros a los modelos hegemónicos (Parrini, 2016). De esta manera, la aparición del cuidado estético del cuerpo en los hombres en determinados contextos socioculturales ya no necesariamente pondría en duda su masculinidad, y hasta incluso puede ser entendido como nueva exigencia del ser hombre, proporcionando nuevas características al modelo referencial de la masculinidad hegemónica, donde se hibridan modelos tradicionales de masculinidad hegemónica con las tradicionalmente subordinadas.

\section{Diseño metodológico}

El diseño metodológico recoge el planteamiento de Casado y Lasén (2014), en cuanto a las nuevas posibilidades que dan las Tecnologías de la Información y la 
Comunicación [TIC] para generar nuevas técnicas metodológicas que se adapten a los nuevos objetos/sujetos de estudio. Siguiendo con la crítica de las autoras, éstas entienden que las TIC propician prácticas emergentes que requieren de la innovación metodológica para atender mejor a los elementos narrativos y discursivos de la acción social.

A partir de este enfoque, se optó por un diseño de base cualitativo, siguiendo los siguientes puntos: La población con la que se trabaja es la de usuarios masculinos de Instagram que suben fotos de ellos mismos del tipo antes y después, etiquetadas con alguno de los cuatro hashtags seleccionados. La muestra, por las propias particularidades del estudio cualitativo y por los inconvenientes encontrados para establecer la población de referencia por las propias características de Instagram $^{3}$, es de tipo no representativa, por lo que los resultados obtenidos del análisis circunscriben únicamente a las publicaciones observadas, siendo no-generalizables. El proceso de muestreo ha sido de tipo secuencial. Este tipo de muestreo, es no representativo, no probabilístico, no aleatorio e intencional. Según Valles (1999), es un muestreo teóricamente conducido, donde el investigador desarrolla una planificación para escoger los datos requeridos durante un determinado intervalo de tiempo. Al mismo tiempo, es un muestreo que se ajusta a aquellas situaciones de rareza y novedad en la población.

En primer lugar se seleccionaron los hashtags a utilizar, para lo cual se elaboró un proceso de secuencia para establecer un calendario de recogida de publicaciones a lo largo de toda una semana (siete días) en la que se recogían las fotos que aparecían por la mañana, por la tarde y por la noche. En el proceso de selección de las fotos, se ha seleccionado solamente aquellas propias del usuario que la subía.

El objetivo a la hora de elegir los hashtags era identificar en cuáles de éstos había fotos de antes y después. Dichas fotos poseen generalmente la característica de presentar una foto partida en dos partes, donde la parte izquierda recoge una imagen del pasado del sujeto y la parte derecha una de la actualidad, con la clara intención de mostrar la evolución positiva de la persona en términos corporales.

Para llegar a la selección de los cuatro hashtags definitivos, se partió del hashtag \#antesydespues, desde el cual, a través de una búsqueda de tipo "bola de nieve", se identificaron los principales hashtags en los que aparecen fotos de antes y después. Posteriormente, se hizo un proceso de selección y descarte de los distintos hashtags, hasta llegar a la decisión de la selección de la utilización de cuatro definitivos: \#beforeandafter, \#weightloss; \#transformationtuesday; \#weightlossjourney.

Una vez hecha esta primera secuencia de recogida que contó con 141 publicaciones, se hizo un primer análisis exploratorio de las publicaciones con el fin de saber si se había producido la saturación informativa. Tras este primer análisis se entendió que sí se había alcanzado el criterio de saturación, algo ya sospechado durante el propio proceso de recogida, debido a que las características de las fotos y de los comentarios son muy

\footnotetext{
${ }^{3}$ Por las características propias de Instagram, no se puede tener información exacta de cuántos usuarios masculinos han subido este tipo de fotos ni su información sociodemográfica. Los perfiles de éstos no especifican ni edad, ni nacionalidad o ciudad de residencia, y por ese motivo no se ha podido realizar una clasificación por edades a la hora del análisis, ni tampoco restringir la población de estudio a una región geográfica específica. Esto puede acarrear algún inconveniente a la hora de la interpretación de la observación de las fotos, y se tendrá en cuenta a la hora del análisis
} 
similares entre los usuarios, aspecto en el cual se profundizará en los apartados analíticos.

Para el análisis explicativo e interpretativo de las publicaciones, se tomaron las fotos y el texto que algunos usuarios introducen. En el caso de las fotos, se realiza un análisis que recoge algunos aspectos del planteamiento analítico semiótico para las imágenes, pero sin llegar a realizarlo con sistematicidad. El objetivo proponía interpretar el significado que los sujetos buscan dar, y cuál es la interpretación social de los mismos. Por eso se entiende oportuno el enfoque semiótico, que busca descifrar signos y significados en conexión con el contexto social y cultural existente (Karam, 2014).

A la hora del análisis de las fotos, es importante tener en cuenta la principal característica que tienen éstas, y es el hecho de ser selfies. El término selfie es un anglicismo que puede ser entendido en castellano como una "auto-foto". Lasén (2012) explica que el proceso del selfie contiene tres aspectos: "presentación (del cuerpo y del yo), representación (para uno mismo y para los demás) y corporealización o encarnación (embodiment), esto es configuración e inscripción de los cuerpos" (p.9). Es decir, el selfie es una acción de autorreconocimiento y de interacción social por medio de las RRSS, en la cual se hace una representación del yo. Así pues, no podríamos hablar del selfie como un acto netamente narcisista. A su vez, éste no es solamente una foto de sí mismo, sino que es una foto del individuo haciendo o siendo algo en un determinado momento, que por las características propias del selfie, es el ahora. El selfie es un acto en el cual el individuo busca resaltarse ante el resto de los posibles destinatarios de la foto, en la cual hay un fuerte carácter individualista, debido a que el yo y la acción es lo importante y ambos son indisolubles (Broullón-Lozano, 2015).

En el análisis de los textos, dado que éstos no siempre están presentes y es muy variable la función que cumple en la publicación, se ha decidido hacer un análisis de contenido (Valles, 1999) a algunos discursos que se repiten en varios de los usuarios, buscando identificar tendencias en el significado de los discursos que se han recogido, procurando interpretar el sentido que el usuario pretende dar en los mismos. 


\section{Presentación de los resultados}

A continuación se presentan los resultados obtenido en el análisis de las 141 fotos recogidas de diferentes usuarios de Instagram.

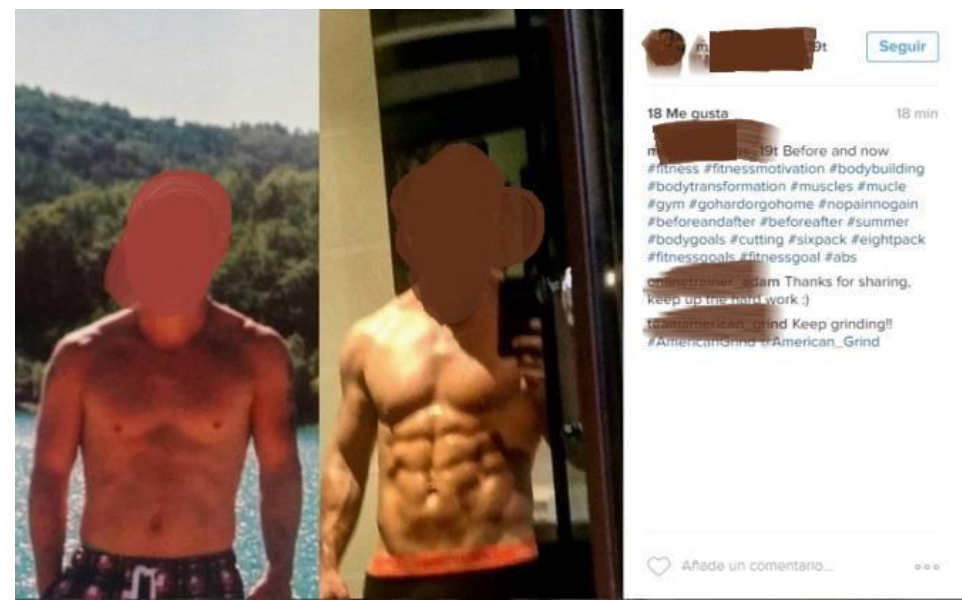

Imagen 1: Recuperada el 2 de agosto de 2016 en Instagram.com

En el análisis visual de las fotos, se ha podido observar que los usuarios se hacen las Fotos de Después [FD] con la intensión de mostrar su transformación corporal. Transformación que va en dos sentidos: pérdida de peso y aumento de musculatura. Las de pérdida de peso suelen presentar al usuario con su camiseta puesta, mientras que las de musculatura suelen mostrar, tanto en el antes como en el después, al sujeto sin camiseta. Por otra parte, se observa un alto grado de intimidad en la toma de la FD, las cuales suelen ser sacadas en espacios hogareños como dormitorios y aseos, a diferencia de las Fotos de Antes [FA] que en muchos casos, son fotos antiguas que no tenían como fin el mostrar el estado corporal del individuo. Relacionado con esto último, las FA suelen ser fotos casuales, en la cual el individuo suele aparecer sonriendo, aspecto que se diferencia de las de después, donde el sujeto aparece normalmente serio o mirando la cámara de fotos con la cual se hace el selfie, reflejando ante un visionado rápido de las fotos, una mayor alegría en las FA que en las FD, aspecto que se contradice con el discurso que los propios usuarios escriben, que se presenta en el siguiente apartado. 


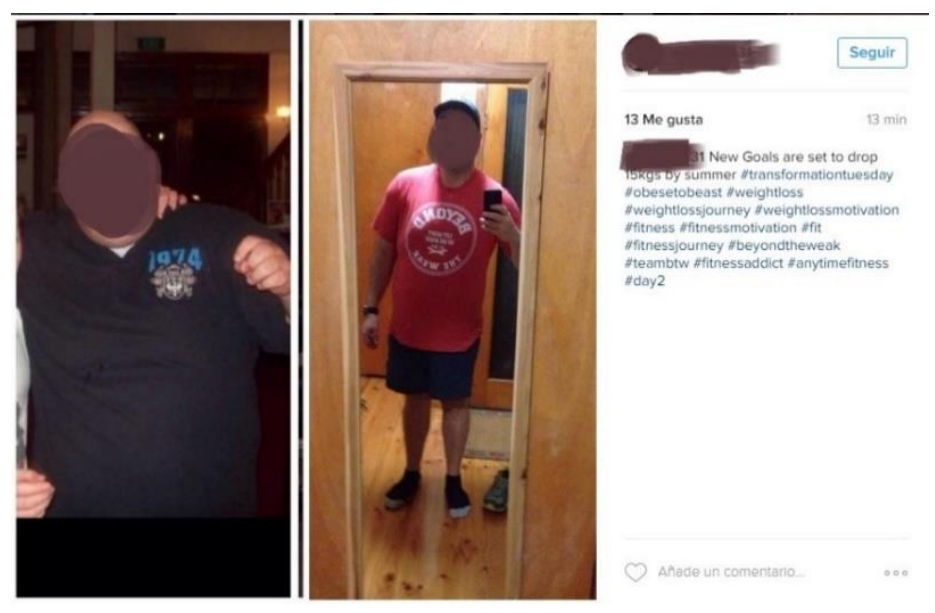

Imagen 2: Recuperada el 1 de agosto de 2016 en Instagram.com

En los textos que acompañan a las fotos, se producen diferencias discursivas entre aquellos usuarios que suben fotos de pérdida de peso y los que suben fotos de aumento de musculatura. Dentro de los primeros, uno de los elementos más llamativos se encuentra en la estigmatización que hacen de su cuerpo pasado, existiendo una desidentificación de ese cuerpo con el propio yo del sujeto: "la foto de la izquierda muestra a alguien que era complaciente y se conformaba con su vida, en la foto de la derecha, se ve a alguien que no se conforma con las normas y trabaja súper fuerte"4. Estos usuarios marcan una clara relación entre su gordura y el propio carácter de su personalidad, "por mucho tiempo he odiado la imagen que veía al verme al espejo (...) no quería juntarme con otras personas y me deprimía". Del mismo modo, indican un claro desencuentro con su propia imagen "cuatro años atrás me encontraba en un sito muy oscuro, era gordo con presión alta y colesterol (...) no me podía mirar en el espejo (...) me estaba lentamente destrozándome a mí mismo". Al pasar a hablar de la foto del presente, resaltan lo increíble que les resulta su transformación, sobre todo en cuanto a la desidentificación con su cuerpo pasado: "aún queda mucho progreso, pero ya ni siquiera recuerdo a esa persona de la foto de antes".

${ }^{4}$ Muchos de los usuarios son de habla inglesa, las citas que aparecen en el trabajo, han sido traducidas del inglés al castellano por el autor del artículo. 


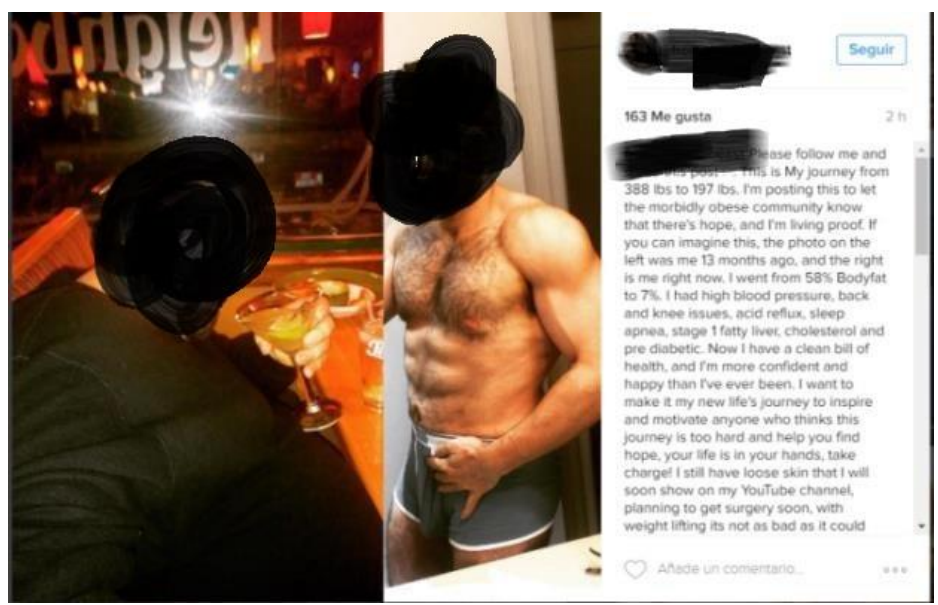

Imagen 3: Recuperada el 28 de julio de 2016 en Instagram.com

Siguiendo con las fotos del presente, los usuarios remarcan la felicidad que tienen por haber conseguido la transformación y una mejor relación con su cuerpo actual: "siempre me he sentido inseguro de mostrar fotos sin mi camiseta puesta, pero no hoy, hoy me siento orgulloso de postear esta foto, porque puedo ver mi progreso". La felicidad actual está relacionada, para muchos de estos usuarios, con el nuevo estado corporal, al mismo tiempo que se describen como personas más seguras. Así también, expresan directamente la felicidad que consiguen con su nuevo cuerpo: "empezando a ver los resultados y a sentirme bien"; "soy mucho más feliz ahora de lo que lo era antes".

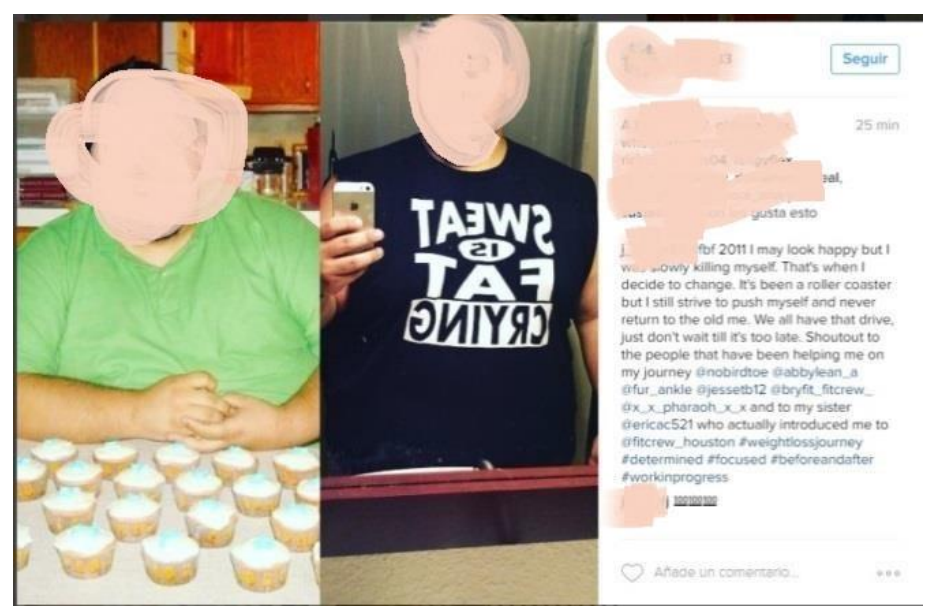

Imagen 4: Recuperada el 3 de agosto de 2016 en Instagram.com

Siguiendo con los usuarios de pérdida de peso, otro rasgo interesante observado se encuentra en el discurso inspirador que estos hacen, tanto hacia sí mismos, como hacia otros usuarios. Esto se entiende en el hecho de que la publicación de estas fotos 
es un aspecto motivador para el proceso de transformación corporal que llevan a cabo los propios usuarios: "nada como las fotografías para mantenerte motivado". Al mismo tiempo que es auto-motivador, busca también inspirar a otros a seguir por el mismo camino: "Mi transformación corporal, persistencia, determinación y trabajo duro. Si yo pude tú también puedes". Se identifica una relación de cofradía entre este tipo de usuarios, los cuales emplean un discurso que busca hacer que las otras personas con sobrepeso puedan alcanzar la felicidad alcanzada por ellos con su transformación, sobreentendiendo que el tener sobrepeso es una causa de angustia: "posteo esta foto para motivar a todas las personas obesas de que hay esperanzas"; "Tú puedes hacer todo si pones en tu mente que puedes hacerlo, no pierdas las esperanzas". En este discurso motivador, aparece un elemento sumamente interesante, y es la asociación entre no tener sobrepeso y ser mejor persona: "estoy aquí para motivar a otros a ser mejores".

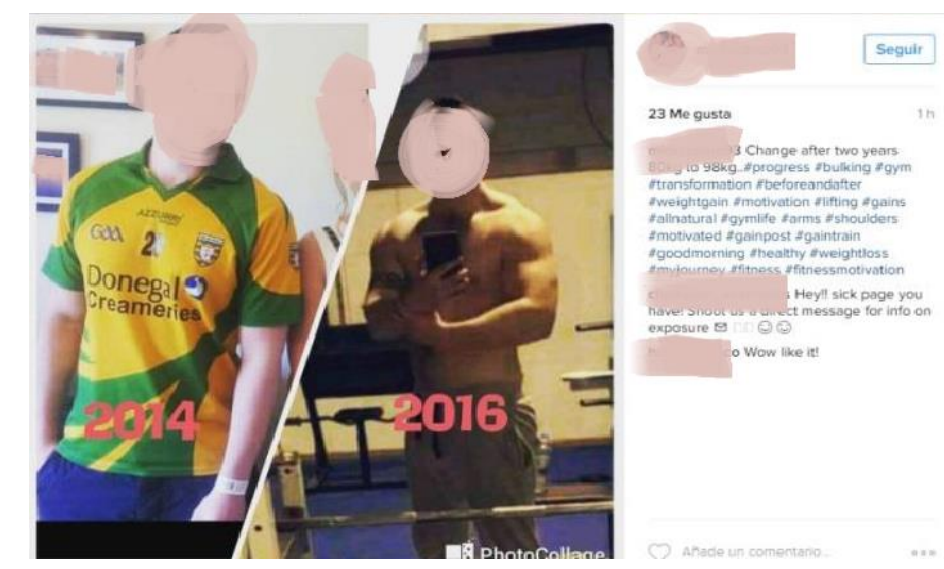

Imagen 5: Recuperada el 28 de julio de 2016 en Instagram.com

El discurso inspirador se encuentra vinculado a la idea de éxito, progreso y estilo de vida. En este último sentido, algunos usuarios remarcan haber cambiado la forma en que llevaban a cabo su vida y que dicho cambio ha sido una decisión propia: "Un día decidí cambiar el camino por el cual iba", así se remarca la responsabilidad que tiene el propio sujeto con su propia felicidad: "el perder peso está en ti". En cuanto al éxito y al progreso, existe la idea de que el proceso de transformación corporal es un proceso constantemente inacabado hacia el éxito y alcance de los objetivos: "no hay secretos para el éxito, es un resultado directo del trabajo duro, preparación y aprendizaje de los errores, es un camino muy largo a seguir". En esta parte del análisis, empiezan a aparecer las transformaciones corporales de aumento de musculatura; el discurso del progreso, el trabajo duro y el seguir hacia delante es más propio en este tipo de usuarios, sosteniendo la idea de que la transformación corporal es un constante ir hacia delante: "me siento fantástico y emocionado de seguir motivándome a seguir hacia delante". 
Revista Punto Género № 12. Diciembre de 2019

ISSN 0719-0417/ $126-147$

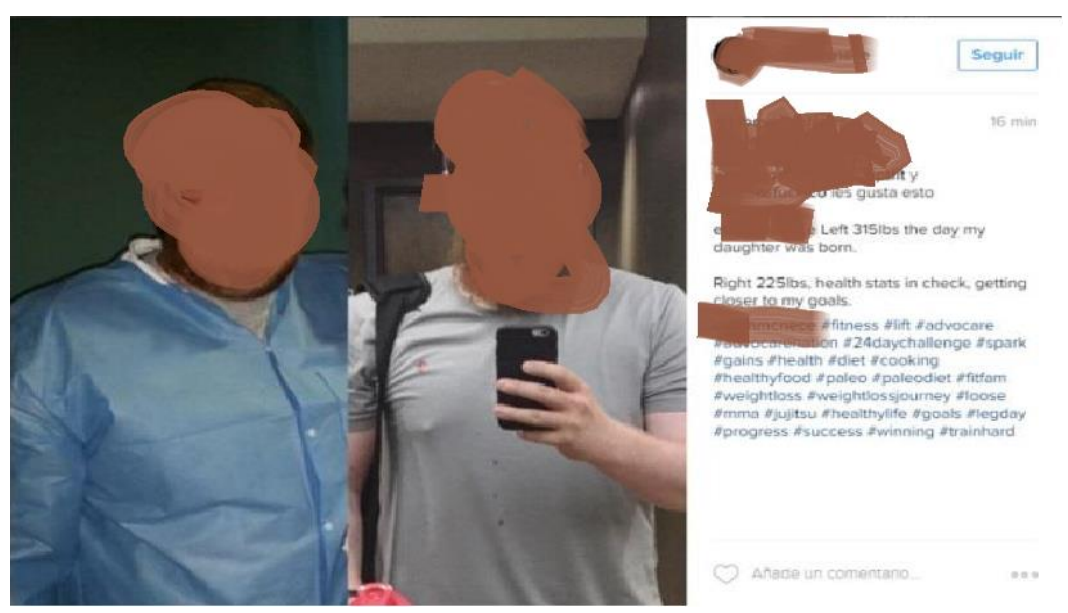

Imagen 6: Recuperada el 7 de agosto de 2016 en Instagram.com

La alusión al trabajo duro es una de las muletillas más utilizadas por los usuarios, sobre todo en aquellos que buscan el aumento muscular. Estos remarcan aspectos como la disciplina, el esfuerzo y la dificultad que existe en el cambio: "el cambio no viene fácil, hay que trabajar en él". En este tipo de usuarios hay una clara vinculación al sacrificio y al dolor para alcanzar los objetivos que se persiguen: "me he estado matando en el gimnasio para conseguir lo que quería": "me he estado matando durante tres semanas, y ahora vendrán otras seis más duras". La determinación y el logro de los objetivos también aparecen en este tipo de discurso, "hay que estar determinado para conseguir los objetivos", en donde el esfuerzo y la constancia lo es todo: "la fuerza no viene de ganar, solo la lucha trae la fuerza". Por último, resulta interesante mencionar, que muchos de los que escriben sobre su aumento muscular, lo hacen detallando características, en cuanto a que mencionan porcentajes de aumento de masa muscular y de niveles de grasa en el cuerpo, que quizás en muchos casos, al ojo no especialista en musculación, es de difícil identificación. 


\section{Discusión}

A continuación se discutirá el análisis de las fotos y los textos de las distintas publicaciones, a partir de la teoría previamente presentada.

\section{Angustia y felicidad a través del propio cuerpo}

Se ha podido observar tanto en el análisis de las fotos como de los textos, que los usuarios analizados realizan una estigmatización hacia su cuerpo pasado, al cual identifican como su antiguo yo. Hay un señalamiento hacia su yo pasado vinculado a la gordura y con el que no se identifican en la actualidad y hacia el cual, en muchos casos, sienten aversión. Esto se emparenta con el planteamiento de Bordo (2001), en cuanto a que en la actualidad muchos hombres empiezan a sentirse inseguros con su propio cuerpo, de forma similar a los problemas de inseguridad corporal que atañen a las mujeres desde décadas atrás. Dicha inseguridad se busca subsanar de forma individual y vinculada a lo corpóreo como lo plantea Callejo (2005), siendo el propio cuerpo de los sujetos un elemento al mismo tiempo de seguridad y de salvación para ellos. La seguridad viene por medio de adscribirse a la norma social que en este caso reniega de los cuerpos imperfectos, vinculados tanto al sobrepeso como a la delgadez no musculada. Este punto se encuentra en sintonía con los aportes de Butler (2002) y Preciado (2002), donde se observa una naturalización en cuanto a qué tipos de cuerpos deben ser estigmatizados y cuales otros deben ser seguidos como normativos. Asimismo, podemos apreciar y entender que los usuarios expresan la existencia de una presión social en relación a qué cuerpo se debe tener. Es así, éstos hacen una relación directa entre el seguir o no la norma corporal, con el estado de felicidad o infelicidad de ellos mismos.

En la búsqueda de la felicidad y la idea de proyectos corporales, se observa que los usuarios, tienen presente su relación con su pasado y su futuro. Hay una clara (y evidente) relación con su propio pasado, puesto que éste es el marco de referencia que los individuos poseen para motivarse en el presente. El cambio que se hace respecto al pasado es lo que motiva al usuario. Al mismo tiempo, éstos plantean en sus discursos la idea de que su situación corporal actual es de tránsito hacia una mejor situación posterior, estando así presente la idea de futuro en el imaginario y en la motivación de los mismos. Por ello, parece cuestionable la tesis del presentismo planteada por autores como Lipovetsky (1991) en los usuarios analizados, los cuales se adhieren a una idea de progreso constante hacia un destino no muy claro, pero que está vinculado con un estado de perfección corporal futuro.

\section{Una identidad corporal}

La desidentificación con el cuerpo pasado se contrapone con la identificación con

el actual, del cual dicen sentirse orgullosos, al mismo tiempo que hacen referencia a un nuevo yo diferente al anterior. Es interesante observar cómo los usuarios identifican su identidad o su propio yo, al tipo de cuerpo y apariencia que poseen, en el mismo 
sentido que planteaba Baudrillard (2009), en cuanto es la apariencia poseída por el sujeto lo que marca (en mayor o menor medida) la identidad del sujeto. Siguiendo con este autor, volvemos a la idea planteada en el apartado anterior, de que el cuerpo es un espacio de salvación para el propio individuo, volviendo el cuidado del mismo y de su estética un proyecto personal. Este aspecto se relaciona con lo planteado por Alonso (2007), cuando afirma que en la posmodernidad los proyectos colectivos han sido en buena medida dejados de lado por proyectos de tipo personal, siendo pocas cosas tan personales como lo es el propio cuerpo. Se puede entender que existe una sacralización del cuerpo propio, en cuanto a que se da una dogmatización del cuidado del cuerpo y la apariencia, constituyendo para estos usuarios un modo de vida donde encuentran la fortaleza emocional (salvación personal) que quizás, no encuentren en otros aspectos de su vida.

Observamos así que los usuarios se reconocen y se aceptan a sí mismos por medio de su transformación corporal, habiendo en este caso una auto-aceptación personal, la cual, necesita también del reconocimiento del resto de las personas. Como se ha visto, el proceso de transformación corporal no es únicamente hacia dentro, sino que también busca la aprobación externa. Se aprecia en el análisis que los usuarios adoptan este proceso de transformación corporal no solo como un proceso, sino también como un estilo de vida en sí mismo. Debido a que, - siguiendo a Giddens (1995) -, éstos realizan prácticas sociales rutinarias que generan una identidad del yo, enmarcada en un tipo de estilo de vida especifico, que categoriza al sujeto dentro de la estructura social, al mismo tiempo que le otorga su propia identidad. De ahí que los usuarios hablen de reconocerse (o no) como ellos mismos, en cuanto a la imagen corporal que muestran. Este punto puede relacionarse con lo planteado por Lash (1997), en cuanto a que en la posmodernidad los sujetos no se adhieren a referentes colectivos vinculados a los modelos de producción, sino que se incorporan a categorías múltiples vinculadas a elementos de consumo.

\section{Disciplina y consumo}

En el análisis de los textos que acompañan a las fotografías, se ha observado que existe un discurso auto-referencial por parte de los usuarios, quienes afirman que el proceso de transformación corporal -así como el mal estado corporal antiguo- es responsabilidad del propio sujeto. Aquí aparecen elementos como: auto-disciplina, autocontrol, auto-exigencia o auto-aceptación. Este aspecto entronca con el planteamiento de Bauman (2003), donde en la posmodernidad, es en el sujeto en el que recaen todas las responsabilidades, tanto de los éxitos como de los fracasos, produciéndose un estado donde el individuo está en una constante auto-exigencia consigo mismo y con sus resultados obtenidos, produciéndose una moral del yo.

Este aspecto de la auto-responsabilidad con el cuerpo, fomenta disciplinas corporales, que encuentran conexión con el planteamiento de Foucault (1998), al respecto del proceso disciplinador que las estructuras de poder ejercen mediante el (auto) control del cuerpo. Resulta interesante observar que los usuarios plantean un discurso 
de liberación personal, relacionado con su transformación corporal, que se contradice con todo el trabajo, disciplina y autocontrol que estos hacen para realizar la transformación. Aquí la perspectiva sobre el poder de Foucault encaja a la perfección, en cuanto a que los sujetos se enorgullecen de la liberación de un estado, que ellos mismos clasifican de opresor, aceptándolo como tal. Se observa también que los usuarios alardean del esfuerzo y el trabajo duro que han tenido que hacer para alcanzar la transformación. Esto se puede vincular al gusto por el sacrificio; visto desde otra manera, como un sacrificio a rendir en aras del culto al cuerpo propio, del cual los usuarios sienten orgullo. Cabría relacionar esto último con lo planteado por Baudrillard (2009), donde las funciones de las instituciones religiosas de antaño han sido transferidas al sujeto como un sujeto/objeto de consumo.

Aquí nuevamente aparece lo planteado por Bauman (2003), en tanto que el buen estado corporal es un bien de consumo. Se puede entender que los usuarios, al estar participando del proceso de transformación corporal -tanto publicando como siguiendo y comentando-, están siendo consumidores de un tipo específico de estado corporal. Éste asimismo les provee de las características de la identidad vinculadas al cuidado del cuerpo.

\section{El componente masculino}

En cuanto a las masculinidades, encontramos un aspecto interesante en la estigmatización que realizan los usuarios de cierto modelo de cuerpo masculino, en cuanto a que éstos (como hombres) ven impropia la gordura o la delgadez no musculada. Siguiendo a Connell (1995), se puede interpretar que la representación cultural que los usuarios poseen de la masculinidad está ligada al hombre con un buen estado físico, delgado y musculado. Transfiriendo este aspecto a la interpretación de la masculinidad que hacen autores como Bourdieu (2000), donde la identidad masculina es una identidad de oposición, podemos definir que, para estos usuarios, el ser masculino no debe ser: ni gordo, ni delgado no musculado.

Asimismo, en el discurso de los usuarios de pérdida de peso, el relato de su proceso de transformación corporal está cargado de una fuerte apertura emocional, realizando descripciones muy personales de su situación anterior, del sufrimiento pasado y de la alegría presente. En este sentido, la apertura emocional se opone al tipo de hombre tradicional, que se caracterizaba por la hosquedad en este aspecto. Cabe remarcar que dicha apertura emocional es parte de un discurso de superación, es decir, el discurso de los usuarios es de enaltecimiento del propio yo, en el cual hay una crítica a su yo pasado, por lo que se busca el (auto) reconocimiento propio a través de la consecución del cuerpo ideal masculino. Reflejando la relevancia del ser importante para estos sujetos, aspecto muy vinculado a la masculinidad tradicional (Marqués y Osborne, 1991).

Por otra parte, aparecen en juego otros rasgos en las publicaciones vinculados a la masculinidad tradicional, como: la lucha por los objetivos; el ir siempre hacia delante, la perseverancia; el no darse por vencido; el trabajo duro; la fuerza física. Estos elementos, se relacionan con ciertos valores de la cultura capitalista vinculados al 
esfuerzo y al éxito. A su vez, la presencia de la agresividad en los gestos en muchos usuarios tras la transformación corporal, refleja otro componente masculino tradicional en éstos, los cuales vinculan a su nuevo yo musculado, con la identidad masculina ideal, que debe de tener un aspecto de seriedad y agresividad en su rosto. Es así que -siguiendo a Demetriou (2001)- los usuarios presentan modelos de masculinidad híbridos, en donde aparecen entremezclados aspectos de la masculinidad tradicional con elementos de nuevas masculinidades.

No aparecen en los textos alusiones al cuidado de la salud por parte de estos hombres. El cuerpo se vincula a una cuestión de felicidad y de auto-realización, pero no hay cuestionamiento sobre la salud, tanto en el cuerpo pasado como en el presente. Se puede ver que el proceso de transformación corporal de estos usuarios, aparentemente no contrae consecuentemente una mayor preocupación del cuidado de la salud del mismo.

\section{El ritual emocional del antes y después}

A lo largo de los distintos apartados de la discusión de los resultados, se ha repetido la presencia del aspecto motivador y emocional que la publicación de estas fotos representa para los usuarios. Se ha visto que los usuarios se aceptan a través de su nueva apariencia corporal, pero que dicha aceptación requiere de la aprobación -por medio de comentarios y/o "me gustas"- por parte de otros usuarios. El hecho de publicar una fotografía propia en una red social como Instagram, y al mismo tiempo ponerle uno -o varios- hashtags para que dicha foto alcance a un determinado tipo de usuarios, refleja que el fin de esa publicación no es únicamente de tipo narcisista, sino que es una acción con un fin relacional. En este caso, vemos que aparecen nuevas formas de cohesión social -en términos de Beck (1998)-, por medio de nuevas herramientas comunicativas, que fomentan nuevas y diferentes formas de relación entre los sujetos. Es así que los usuarios no solamente persiguen fines narcisistas, como explica Lipovetsky (1991), sino que por el contrario, están llevando a cabo nuevas formas de relacionarse con otras personas (Lasén, 2012). Siguiendo con Lipovetsky, el carácter individualista sí está presente en los usuarios, pero éste no es un individualismo egoísta como explica el autor, sino un individualismo relacional e inclusivo, en cuanto a que los usuarios necesitan ser partícipes de un colectivo para sentirse motivados. Este aspecto, se relaciona con lo planteado por Rifkin (2010), en cuanto a la necesidad de los individuos posmodernos de intentar llamar la atención con el fin de ser parte de algo.

En este sentido, es interesante reflexionar sobre la paradoja de la posmodernidad que menciona Beck (1998), en cuanto a que se vive en sociedades individualistas en las cuales, las personas no pueden solucionar sus problemas de forma totalmente autónoma, requiriendo del apoyo emocional externo. Aquí entran los planteamientos de Rifkin (2010), puesto que en las sociedades actuales, existe una alta carga relacional y emocional. Lo contradictorio de esto -en el caso específico de este trabajo-, es el choque que este modelo encuentra con el ideario neoliberal del "hazlo tú mismo" y del individualismo, fomentando la dicha paradoja de Beck, donde en la 
sociedad del "auto-todo" (auto-ayuda, auto-exigencia, auto-dependencia, autoaceptación, auto- disciplina, etc.), los individuos poseen una dependencia emocional ligada a la aprobación de los otros y la integración en algún colectivo social.

\section{Conclusiones}

El análisis de las publicaciones fotográficas ha mostrado que para los usuarios analizados, la imagen y el estado corporal es un aspecto que los instruye identitariamente. Aporta tanto seguridad y autoestima al sujeto, como también, fomenta la adopción de estilos de vida concretos. Los usuarios se auto identifican en buena medida en función del tipo de cuerpo que poseen, existiendo una estigmatización hacia los cuerpos no normativos. En este sentido, se puede afirmar que los usuarios tienen proyectos de vida en los cuales la búsqueda de un tipo ideal de cuerpo es parte más que importante de estos proyectos. Siendo un aspecto motivador para los usuarios, en el cual encuentran un objetivo para sus vidas.

Por otra parte, se ha entendido que la acción de publicar una foto de la transformación corporal propia, no supone un acto netamente narcisista o egoísta, sino que tiene, en parte, objetivos relacionales de los usuarios. Éstos buscan conseguir, por medio de la publicación de estas fotos, la motivación externa para seguir con su proyecto, al mismo tiempo que buscan motivarse inspirando a otros a seguir el camino que ellos creen de éxito. La acción de publicar la foto por parte de los usuarios, se vuelve un ritual de interacción exitoso para estos, y lleva a los usuarios a entender dicho proceso como un estilo de vida en sí mismo.

El vínculo entre lo masculino y lo corpóreo queda más que en evidencia en el fuerte peso que tiene la relación sujeto/cuerpo en la forma en que los usuarios elaboran su propia identidad. La relación sujeto/cuerpo no es una relación entre dos aspectos diferentes, sino que es una relación interna de una misma cosa. Por ese motivo y siguiendo lo planteado por Turner (1989), no podemos entender al sujeto sin el cuerpo, ni al cuerpo sin el sujeto. La identidad masculina de los usuarios se encuentra fuertemente marcada por la percepción que éstos tienen de su cuerpo, y la forma como ese cuerpo les permite relacionarse con el resto de los usuarios, ubicando al sujeto en un determinado rol y estatus social. Siguiendo a Esteban (2004), se reafirma que el cuerpo es un espacio relacional, porque en gran parte, toda práctica social es una práctica corporal. Es así que, tras el análisis, encontramos que la identidad masculina de los usuarios está fuertemente orientada por la presencia de un cuerpo normativo masculino, que produce en estos, angustia y depresión en el caso de no poseerlo y confianza y alegría en el caso de que sí lo posea. Se genera así, por medio de la relación exitosa con el cuerpo normativo, un tipo de identidad que busca enmarcarse dentro de los hábitos y conductas que llevan a la obtención y mantenimiento de ese tipo de cuerpo. El mandato de masculinidad estaría también regido en estos casos, por poseer una corporalidad normativa, que desprecie aquellos cuerpos con sobrepeso o no musculados.

Los valores del culto al cuerpo, dentro de la sociedad de consumo, están más que presentes en los usuarios analizados. Siguiendo el objetivo general del trabajo, se 
observa que los usuarios generan proyectos de vida personales, guiados por la necesidad que sienten de tener un cuerpo normativo. Dicha necesidad, fomenta que éstos proyecten sus anhelos y esperanzas personales en pos de conseguir el cuerpo ideal, sacralizándolo y volviéndolo objeto de deseo y de consumo. Los usuarios rinden culto al ideal de cuerpo masculino, observándose que el no poseer dicho ideal corpóreo, es motivo de estigmatización por parte de estos. En este sentido, se observa una presión social existente en los usuarios, en cuanto a un tipo de cuerpo que como hombres estos deben de tener.

\section{Bibliografía}

Aguiar de Souza, J.C., (1998): “Ámame por ser bello! Masculinidad=cuerpo+eros+consumo", en Revista de Estudios de Género. La ventana, Vol. 1, No. 8, p.269-283.

Alonso, Luis Enrique (2007): "La globalización y el consumidor: Reflexiones generales desde la sociología del consumo". Mediterráneo económico, No 11, p.37-56

Augé, Marc (1994): Los "no lugares". Espacios del anonimato. Una antropología de la sobremodernidad. Barcelona: Gedisa

Barreto Vargas, Carmen Marina (2011): "Transgresiones corporales, rituales de belleza y seres poshumanos”. Atlántida, en Revista Canaria de Ciencias Sociales, No. 3, p.17-34.

Baudrillard, Jean (2009): La Sociedad de consumo: sus mitos, sus estructuras. Madrid: Siglo XXI

Bauman, Zygmunt (2003): Modernidad liquida. Buenos Aires: Fondo de la cultura económica.

Beck, Ulrich (1998): La sociedad del riesgo: hacia una nueva modernidad. Barcelona: Paidós

Bordo, Susan (2001): "El feminismo la cultura occidental y el cuerpo", en Revista de estudios de género. La ventana, No. 14, p.7-81.

Boscán, Antonio (2008): "Las nuevas masculinidades positivas", en Utopía y praxis latinoamericana, No. 41, p.93-106.

Bourdieu, Piere (2000): La dominación masculina. Buenos Aires: Anagrama.

Broullón Lozano, Manuel (2015): "Por una semiótica del selfie en la cultura visual digital", en Fotocinema: revista científica de cine y fotografía. No. 11, p.215-234 
Butler, Judith (2002): Cuerpos que importan: sobre los límites materiales y discursivos del "sexo". Buenos aires: Paidós

Callejo, Javier (2005): "Modos de consumo y sociedad del riesgo", en Revista Internacional de Sociología, Vol. 63, No. 3, p.133-157

Casado, Elena y Lasén, Amparo (2014): "Epílogo: controversias y desasosiegos metodológicos", en Lasén y Casado (Comp) Mediaciones tecnológicas. Cuerpos, afectos y subjetividades, Madrid: CIS, p.153-163.

Connell, Raewyn (1995): Masculinidades. México D.F: Universidad Nacional Autónoma de México, Programa Universitario de Estudios de Género

De Keijzer, Benno (2016):"Sé que debo parar, pero no sé cómo": Abordajes teóricos en torno a los hombres, la salud y el cambio", en Sexualidad, Salud y Sociedad - Revista Latinoamericana, No. 22, p.278-300

Demetriou, Demetrakis (2001): “Connell's concept of hegemonic masculinity: A critique", en Theory and society. Vol. 30, No. 3, p.337-361.

Enguix, Begonia (2012): "Cultivando cuerpos, modelando masculinidades", en Revista de Dialectología y Tradiciones Populares, Vol. 67, No. 1, p.147-180.

Esteban, Mari Luz (2004): Antropología del cuerpo: género, itinerarios corporales, identidad y cambio. Barcelona: Bellaterra

Entwistle, Joanne (2002): El cuerpo y la moda: una visión sociológica. Barcelona: Paidós.

Ferreiro Habra, Ana Carolina (2018): "Las masculinidades en el discurso publicitario", en Question, Vol. 1, No. 58, e053

Finol, José Enrique y Finol, David Enrique (2008): "Discurso, Isotopía y Neo-Narcisismo: Contribución a una Semiótica del Cuerpo", en TELOS. Revista de estudios interdisciplinarios en ciencias sociales, Vol. 10, No. 3, p.383-402.

Foucault, Michel (1998): La historia de la sexualidad: Volumen I. Madrid: Siglo XXI

Giddens, Anthony (1995): Modernidad e identidad del yo: el yo y la sociedad en la época contemporánea. Barcelona: Península.

Hatty, Suzanne (2000): Masculinities, violence, and culture. Thousand Oaks, London and New Delhi: Sage 
Karam, Tanius (2014): “Introducción a la semiótica de la imagen”. Portalcomunicación.com, [On Line]. Disponible en http://www.portalcomunicacion.com/lecciones det.asp?id=23

Kornblit, Ana Lía (2004): Metodologías cualitativas en las ciencias sociales. Buenos Aires: Biblos

Lasén, Amparo (2012): “Autofotos. Subjetividades y Medios Sociales”. En García-Canclini y Cruces (Comp) Jóvenes, culturas urbanas y redes digitales. Prácticas emergentes en las artes, el campo editorial y la música. Madrid: Ariel, p.243-262

Lash, Scott (1997): Sociología del posmodernismo. Buenos Aires: Amorrotu.

Lipovetsky, Gilles (1991): El imperio de lo efímero: la moda y su destino en las sociedades modernas. Barcelona: Anagrama.

Maffesoli, Michel (2004): El tiempo de las tribus: el ocaso del individualismo en las sociedades posmodernas. Buenos Aires: Siglo XXI.

Marqués, Josep Vicent y Osborne, Raquel (1991): Sexualidad y sexismo. Madrid: Fundación Universidad-Empresa

Mira, Alberto (2015): “Mario Casas y el hombre de la “espectacularización”", en Área abierta. No. 15, p.15-30.

Parrini, Rodrigo (2016): Falotopías: indagaciones en la crueldad y deseo. Ciudad de México: Universidad Nacional Autónoma de México, Programa Universitario de Estudios de Género.

Preciado, Beatriz (2002): Manifiesto contra-sexual. Madrid: Opera prima

Rifkin, Jeremy (2010): La civilización de la empatía. Madrid: Paidós

Rodríguez Menéndez, Carmen: (2007): "Identidad masculina y contexto escolar: notas para un debate", en Revista de educación, No. 342, p.397-418.

Salcido, Mónica (2010): "Un pequeño sacrificio, pero creo que lo valgo: reflexiones alrededor del culto al cuerpo", en En-claves del Pensamiento, No. 7, p.189-191.

Segato, Rita (2013): Las nuevas formas de la guerra y el cuerpo de las mujeres. Buenos Aires: Tinta limón ediciones

Simpson, Mark (2018): "Spornosexuales: una revolución permanente y espectacular. Sobre la metrosexualidad de segunda generación y su "androginia de los andrógenos", en Quaderns de I'Institut Català d'Antropologia, No. 34, p.157-176. 
Revista Punto Género № 12. Diciembre de 2019

ISSN 0719-0417 / $126-147$

Turner, Bryan (1989): El cuerpo y la sociedad: exploraciones en teoría social. México D.F: Fondo de la cultura económica.

Valles, Miguel (1999): Técnicas cualitativas de investigación social: reflexión metodológica y práctica profesional. Madrid: Cultura libre

Velasco Molpaceres, Ana María (2019): "La moda en los medios de comunicación: de la prensa femenina tradicional a la política y los/as influencers", en Prisma Digital. No. 24, p.153-185. 